\title{
An instrument for the rapid quantification of PM-bound ROS: the Particle Into Nitroxide Quencher (PINQ)
}

\author{
Reece A. Brown ${ }^{1}$, Svetlana Stevanovic ${ }^{1,3}$, Steven Bottle ${ }^{2}$, and Zoran D. Ristovski ${ }^{1,2}$ \\ ${ }^{1} \mathrm{ILAQH}$ (International Laboratory of Air Quality and Health), Queensland University of Technology, \\ George St. 2, Brisbane, 4000 QLD, Australia \\ ${ }^{2}$ School of Chemistry, Physics and Mechanical Engineering, Queensland University of Technology (QUT), \\ Brisbane, 4000 QLD, Australia \\ ${ }^{3}$ School of Engineering, Deakin University, Geelong, VIC 3216, Australia
}

Correspondence: Svetlana Stevanovic (svetlana.stevanovic@deakin.edu.au)

Received: 27 September 2018 - Discussion started: 5 November 2018

Revised: 14 March 2019 - Accepted: 22 March 2019 - Published: 16 April 2019

\begin{abstract}
Reactive oxygen species (ROS) present on or generated by particulate matter (PM) have been implicated in PM-induced health effects. Methodologies to quantify ROS concentrations vary widely, both in detection and collection methods. However, there is currently an increasing emphasis on rapid collection and measurement due to observations of short half-life ROS. To address this problem, this paper details the design and characterization of a novel instrument for the measurement of PM-bound ROS named the Particle Into Nitroxide Quencher (PINQ). This instrument combines the 9,10-bis (phenylethynyl) anthracene-nitroxide (BPEAnit) ROS assay in conjunction with a purpose-built aerosol collection device, the insoluble aerosol collector (IAC). The IAC continuously collects PM regardless of size or chemistry directly into a liquid sample with a collection efficiency of $>0.97$ and a cut-off size of $<20 \mathrm{~nm}$. The sampling time resolution of the PINQ is $1 \mathrm{~min}$, with a limit of detection (LOD) of $0.08 \mathrm{nmol} \mathrm{m}^{-3}$ in equivalent BPEAnit-Me concentration per volume of air. This high sample time resolution and sensitivity is achieved due to a combination of the highly concentrated IAC liquid sample, minimized liquid sample volume, and the rapid reaction and stability of the BPEAnit probe.
\end{abstract}

\section{Introduction}

The World Health Organization (WHO) found air pollution was responsible for more than 7 million premature deaths in 2012. A large contributor to this mortality is atmospheric particulate matter (PM), which has been linked to cardiovascular disease (Chow et al., 2006; Donaldson et al., 2001; Nel, 2005), increases in the prevalence of chronic respiratory disorders (Nel, 2005; Penttinen et al., 2001), and adverse effects in both embryonic and adult neuron activity (Morgan et al., 2011). Furthermore, studies have shown a link between exposure to PM in diesel exhaust and an increased lung cancer risk (Silverman et al., 2012). A consequence of these and other discoveries was that, in 2012, diesel exhaust was classed as a type 1 carcinogen by the International Agency for Research on Cancer (IARC) (Benbrahim-Tallaa et al., 2012).

A key mechanism used to explain these adverse health effects is oxidative stress (Ayres et al., 2008; Li et al., 2002). Reactive oxygen species (ROS) are a group of free radicals which can be either present on the surface of PM (PM-bound ROS) (Hung and Wang, 2001; Venkatachari et al., 2007) or generated through chemical reactions between PM and cells (endogenous ROS) (Donaldson et al., 2002). When inhaled, PM-associated ROS interacts with cells to create oxidative stress, interrupting cell function and potentially leading to cell inflammation and death. The ultrafine particle ranges have been shown to be particularly hazardous in this respect. Their ability to penetrate deeper into tissues than their larger counterparts allows them to collect inside mito- 
chondria, causing major structural damage to cells (Li et al., 2002).

Aerosols generated through combustion processes are of particular concern for oxidative stress as they are a major source of ultrafine particles (Brines et al., 2015; Posner and Pandis, 2015) and their potential for high ROS content (Cho et al., 2005; Kao and S., 2002; Mudway et al., 2005; Ristovski et al., 2012; Zhao and Hopke, 2012). Combustion emissions associated with vehicle emissions, power generation, and biomass burning significantly contribute to the aerosol burden in many heavily populated urban areas (Harrison and Yin, 2000; Ma et al., 2017; Simoneit et al., 2004), making PM-associated ROS a key issue in the assessment and understanding of the health impacts of air pollution. There have been many in vivo investigations involving both the monitoring of human exposure and the exposure of animals and lab-cultivated cells to ROS-containing aerosols (Donaldson et al., 2002; Morgan et al., 2011; Sa et al., 2014; Shi et al., 2006; Shima et al., 2006). Whilst these studies provide us with an understanding of the aforementioned health impacts of PM-associated ROS exposure, they lack the ability to quantify the oxidative potential of aerosols. In order to achieve quantification, a range of different in vitro methodologies have been developed.

\section{Chemical assays}

The measurement of oxidative potential is a complex issue in terms of both sample collection and chemical analysis. In order for measurements to take place, PM must in most cases be collected into a liquid and mixed with a chemical probe. The degree to which this probe reacts with the sample is then measured in order to ascertain a value related to oxidative potential. Many different chemical probes have been used for this purpose, with a detailed review found elsewhere (Hedayat et al., 2015). The reason for this diversity of probes is twofold. First, each probe is only sensitive to a specific range of ROS. Second, it is not known which ROS contributes to oxidative potential and if they contribute equally. As such, the use of the term "oxidative potential" is contentious in the field of in vitro ROS measurements. Whilst these probes measure a certain contribution to oxidative potential, none are true measures of total oxidative potential. This does not mean results are not valuable, as there have been good correlations between probe responses and oxidative stress response. However, all results must be considered in the context of the probe and methodologies must be used and discussed accordingly.

Some probes, including p-hydroxyphenylacetic acid (POHPAA) (Hasson and Paulson, 2003) and ascorbic acid (AA) (Fang et al., 2016; Stoeger et al., 2009), are sensitive to transition metals. The dithiotreitol (DTT) assay is commonly used (Eiguren-Fernandez et al., 2017; Fang et al., 2015; Gao et al., 2017; Li et al., 2002, 2009; Puthussery et al., 2018; Sameenoi et al., 2012, 2013) due to its ability to simulate the reaction responsible for the generation of ROS when PM interacts with cells, making its quantification a measure of endogenous ROS. It is sensitive to quinones and transition metals, as well as some water soluble organic compounds (WSOCs) and humic-like substances (HULISs). DTT typically requires sample reaction times of between 60 min (Puthussery et al., 2018) and $90 \mathrm{~min}$ for accurate quantification (Cho et al., 2005), which potentially limits the time resolution of real-time applications. However, developments in microfluidic sensors have allowed for DTT measurements with reaction times as low as $18 \mathrm{~min}$ (Koehler et al., 2014; Sameenoi et al., 2012).

Currently, 2,7-dichlorofluorescein diacetate (DCFH-DA) combined with a horse radish peroxide (HRP) catalyst is the most commonly used ROS probe in the literature for the measurement of PM-bound ROS (Fuller et al., 2014; Huang et al., 2016b, a; King and Weber, 2013; Venkatachari et al., 2007; Venkatachari and Hopke, 2008; Wang et al., 2011; Wragg et al., 2016; Zhou et al., 2018). This is due to its relatively simple fluorescence-based quantification, potential for semi-continuous monitoring, and sensitivity to several different ROS species. These species include organic peroxides, hydroperoxides, aldehydes, alcohols, and hypochlorite. However, DCFH is prone to several issues, including autooxidation upon exposure to air and sunlight (Stevanovic et al., 2012a); a high background fluorescence and a lack of sensitivity (Pal et al., 2012); and a relatively complex chemistry set-up for implementation, especially in the case of online measurements (Huang et al., 2016a; Wang et al., 2011; Wragg et al., 2016; Zhou et al., 2018). The catalytic activity of the HRP catalyst is dependent upon sample composition (Pal et al., 2012) and a minimum reaction time of $11 \mathrm{~min}$ for quantification with HRP (Zhou et al., 2018) and a $60 \mathrm{~min}$ without HRP (Pal et al., 2012). These attributes make this probe very difficult to work with in the field and highlight the need for an alternative ROS probe for accurate oxidative potential measurements.

Profluorescent nitroxides (PFNs) are a group of chemicals consisting of a nitroxide group bound to a fluorophore (Fairfull-Smith and Bottle, 2008). Initially these molecules are only weakly fluorescent; however upon reaction with free radicals they become highly fluorescent (Blinco et al., 2011). Quantification of these reactions can be achieved by comparing the fluorescence intensities before and after reaction. Several different PFNs have been developed at the Queensland University of Technology, one of which is BPEAnit. When placed into solution with dimethyl sulfoxide (DMSO), BPEAnit has been shown to be sensitive to a broad range of PM-bound ROS (Stevanovic et al., 2012b), in particular those generated in combustion emissions (Miljevic et al., 2010; Stevanovic et al., 2012a). These include carboncentered radicals, nitrogen-centered radicals, sulfur-centered radicals, and peroxyl and hydroxyl radicals when in solution with dimethyl sulfoxide (DMSO) (Hedayat et al., 2015). Fur- 
thermore, its reaction is diffusion limited, allowing for comparatively quick measurement quantification. These characteristics make the BPEAnit a promising assay for the rapid online measurement of PM-bound ROS.

\subsection{Online collection techniques}

Beyond chemical probes, there are several properties of ROS and combustion aerosols which complicate quantification. PM-bound ROS react readily with the atmosphere and other surroundings (Fuller et al., 2014). This is a significant issue with standard filter capture techniques, as the concentration of PM-bound ROS can be skewed due to the decay of collected ROS during long periods of collection and storage prior to measurement (Fuller et al., 2014; Zhou et al., 2018). Therefore, methodologies involving either long periods of collection or delays between collection and measurement risk severely underestimating the concentration of PMbound ROS in an aerosol. Additionally, extraction processes to remove PM from filters for analysis can introduce further positive and negative sample artefacts (Miljevic et al., 2014). To address these issues, methodologies have been developed to rapidly collect PM directly into a liquid for more accurate quantification of PM-bound ROS.

\subsubsection{Steam collection devices}

Table 1 provides a list of the relevant online instruments developed for the quantification of different ROS species contributing to oxidative potential. Each instrument uses a different combination of either the DTT assay or DCFH assay with a method for direct capture of PM into a liquid. The most predominant of these particle collection methods used are steam collection devices (SCDs) (Khlystov, 1995; Kidwell and Ondov, 2010; Simon and Dasgupta, 1995), including the Particle Into Liquid Sampler (PILS) (Orsini et al., 2003; Weber et al., 2001) and the Gas and Aerosol Collector (GAC) (Dong et al., 2012). SCDs utilize condensational growth to achieve high-efficiency collection of ultrafine particles. When in operation, a sample aerosol is continuously mixed with a precisely controlled flow of steam and cooled, creating a supersaturated aerosol. Particles inside this aerosol undergo condensational growth, increasing them to a size typically between 1 and $4 \mu \mathrm{m}$ in diameter (Orsini et al., 2003). These grown particles are then collected into a liquid with a very high efficiency through wetted impaction methods. The direct injection of steam allows for effective supersaturations to be achieved with high flow rates (Hering et al., 2014). For this reason, steam collection devices can achieve highly concentrated samples, as the ratio of aerosol sample flow to liquid collection flow can be maximized.

The PILS reports a collection efficiency of $97 \%$ particle number collection efficiency for particles between 0.03 and $10 \mu \mathrm{m}$ (Orsini et al., 2003), whilst the GAC shows a total mass collection efficiency of $>99.5 \%$ (Huang et al., 2016a).
The distinction between number collection efficiency and mass collection efficiency is important. Whilst the PILS system collects efficiency over all particle modes from fine to coarse, the GAC has a low collection efficiency for particles $<150 \mathrm{~nm}$ (Dong et al., 2012). This is due to high ultrafine losses inside a wetted annular denuder (WAD) (Simon and Dasgupta, 1993, 1995) used for the GACs gas-phase measurements.

The collection method typically used to capture particles in SCDs involves the continuous deposition and washing-off of particles on a solid surface. Hence, this method relies on particles being soluble in the collection liquid for its reported high collection efficiency. An alternative collection method was proposed in a publication focused on developing a system for the collection of virus aerosols. The impactor plate of a PILS was replaced with a wetted-wall PM cyclone, which collects particles into a standing liquid vortex (Orsini et al., 2003). This prevents particles from depositing on a solid surface, allowing them to be captured into the sample liquid for analysis regardless of solubility. Another miniature wetted cyclone system designed to continuously wash the walls of the cone rather than directly collect particles into a liquid has also been coupled to a PILS system (Peltier et al., 2007). Neither of these alternative collection methods have been adapted for ROS measurement.

\subsubsection{Particle collectors}

The particle collector (PC) (Takeuchi et al., 2005) is another particle collection method shared by published PM-bound ROS devices. Names of similar devices include the mist chamber and aerosol collector. Variants of the PC are used in the Online Particle-bound ROS Instrument (OPROSI), the ROS analyser, and the online PM OP instrument systems. The PC operates by collecting PM onto a hydrophilic filter, which is continuously wetted with a fine mist of a capture solution. The capture solution drips off the filter into a collection reservoir underneath, removing the water-soluble portion of the collected PM for analysis. The use of a filter allows for the collection of ultrafine PM with a very high efficiency $(97.7 \%$, Takeuchi et al., 2005) without the need for a condensational growth stage. A disadvantage of the PC system is that the collection reservoir limits the time resolution of the system due to the continuous mixing of new and old samples.

\subsubsection{Liquid spot sampler}

The o-MOCA system (Eiguren-Fernandez et al., 2017) utilizes a Liquid Spot Sampler (LSS) (Hering et al., 2014) to collect particles for analysis. Similar to the SCDs, the LSS system utilizes a condensational growth process to collect ultrafine particles. However, the method of implementation is significantly different. Rather than mixing the sample aerosol with steam, the aerosol instead undergoes a three-stage wa- 
Table 1. List of online ROS instruments and their key characteristics, including a ROS sampling-analysis system (Venkatachari and Hopke, 2008; Wang et al., 2011), OPROSI (Fuller et al., 2014; Wragg et al., 2016), GAC-ROS (Huang et al., 2016a), ROS analyser (Zhou et al., 2018), o-MOCA (Eiguren-Fernandez et al., 2017), online DTT monitoring system (Koehler et al., 2014; Sameenoi et al., 2012), and online PM OP instrument (Puthussery et al., 2018). Limit of detection (LOD) for DCFH systems is given as equivalent $\mathrm{H}_{2} \mathrm{O}_{2}$ concentrations per cubic metre of air. O-MOCA LOD is given as DTT consumption per minute.

\begin{tabular}{lllllll}
\hline Instrument & $\begin{array}{l}\text { Chemical } \\
\text { assay }\end{array}$ & $\begin{array}{l}\text { Collection } \\
\text { method }\end{array}$ & $\begin{array}{l}\text { Insoluble } \\
\text { particles }\end{array}$ & $\begin{array}{l}\text { Sample } \\
\text { flow rate }\end{array}$ & $\begin{array}{l}\text { Time } \\
\text { resolution }\end{array}$ & $\begin{array}{l}\text { Limit of } \\
\text { detection }\end{array}$ \\
\hline $\begin{array}{l}\text { ROS sampling- } \\
\text { Analysis }\end{array}$ & DCFH & PILS & No & $16.7 \mathrm{Lpm}$ & $10 \mathrm{~min}$ & NA \\
$\begin{array}{l}\text { System } \\
\text { OPROSI }\end{array}$ & DCFH & PC & No & $5 \mathrm{Lpm}$ & $\leq 12 \mathrm{~min}$ & $4 \mathrm{nmol} \mathrm{m}^{3}$ \\
$\begin{array}{l}\text { GAC-ROS } \\
\text { ROS analyser }\end{array}$ & DCFH & GAC & No & $16.7 \mathrm{Lpm}$ & $20 \mathrm{~min}$ & $0.12 \mathrm{nmol} \mathrm{m}^{3}$ \\
$\begin{array}{l}\text { o-MOCA } \\
\text { Online DTT }\end{array}$ & DCFH & PC & No & $1.7 \mathrm{Lpm}$ & $8 \mathrm{~min}$ & $2 \mathrm{nmol} \mathrm{m}^{3}$ \\
monitoring & DTT & LSS & Yes & $3 \mathrm{Lpm}$ & $3 \mathrm{~h}$ & $0.15 \mathrm{nmol} \mathrm{min}^{-1}$ \\
$\begin{array}{l}\text { system } \\
\begin{array}{l}\text { Online PM OP } \\
\text { instrument }\end{array}\end{array}$ & PILS & No & $16.7 \mathrm{Lpm}$ & $3 \mathrm{~min}$ & $\mathrm{NA}$ \\
\hline
\end{tabular}

NA: not available.

ter condensational growth process (Hering et al., 2014). The sample aerosol is drawn through a wet-walled tube where it passes through three independently controlled temperature regions. The induced temperature differentials combined with diffusion of water vapour from the wetted walls of the tube lead to condensational growth of $<10 \mathrm{~nm}$ particles (Hering et al., 2014). The grown particles are impacted into a small liquid volume over the period of $3 \mathrm{~h}$ before being pumped off for analysis.

The reliance on diffusion to introduce water vapour to the sample limits the operational flow rate, leading the LSS to use three separate $1 \mathrm{~L} \mathrm{~min}^{-1}$ growth tubes for a total sample flow of $3 \mathrm{~L} \mathrm{~min}^{-1}$. The direct impaction into liquid removes the reliance of the PM to be soluble in the collection liquid, allowing for solubility-independent collection.

\subsubsection{Measurement technique comparisons}

Ultrafine PM concentrations are heavily dependent upon source proximity and atmospheric conditions (Sabaliauskas et al., 2013), which can lead to significant variations over short time periods and distances. This, coupled with the short half-life of some PM-bound ROS species (Fuller et al., 2014; Zhou et al., 2018), indicates that the concentration of PMbound ROS is dynamic and prone to significant changes over short distances and times. Therefore, in order to accurately measure and understand the health impacts of PM-bound ROS, monitors must have time resolutions sufficient to accurately quantify these variations.

The time resolution of the discussed instruments varies widely from $3 \mathrm{~min}$ to $3 \mathrm{~h}$. It is clear that the SCD- and PCbased instruments offer much higher potential time resolu- tions than that of the LLS-based OPROSI. Within the SCDs, the PILS-based systems have, at a minimum, half the time resolution of the GAC-ROS due to its dual gas- and particlephase measurements. This dual measurement also causes the GAC-ROS system to have a low collection efficiency in the ultrafine PM range, indicating that a SCD without a gasphase measurement stage is a superior choice for PM-bound ROS measurements. The PILS-based Online DTT Monitoring System has the highest time resolution of all the discussed instruments. This is in part due to the total sample liquid volume being much lower than the PC-based systems as it does not require a reservoir. For this reason SCDs currently offer the highest potential for high sampling resolution instruments for PM-bound ROS measurements.

Aside from the OPROSI, a common disadvantage shared by all current systems is their inability to reliably collect PM insoluble in the collection solution for analysis. This is problematic, as a significant portion of primary combustion emissions are hydrophobic (Popovicheva et al., 2008), making them insoluble in the aqueous-based solutions used for the DCFH and DTT probes. This can result in an underestimation in measurements which is not possible to correct for in post-analysis of the data using known losses. This is because the water-insoluble fraction represents a distinct group of PM with both a separate physiological impact (Delfino et al., 2010) and different ROS contributions (Verma et al., 2012). Future systems should endeavour to adapt or create new methodologies to allow for the collection of insoluble particles to improve the understanding and toxicity of aerosol oxidative capacity. 


\subsection{Paper focus}

This paper discusses the design and testing of a novel instrument called the Particle Into Nitroxide Quencher (PINQ). The PINQ has been developed to address the need for an accurate and repeatable method of measuring the PMbound ROS present in aerosols. Having been informed from the current literature on the field, the instrument collection mechanism is based on a steam collection device, with PM collected directly into a miniature liquid vortex containing the BPEAnit ROS assay. The fluorescence increase of the BPEAnit probe is measured using a purpose-built flowthrough fluorimeter with a low internal volume and minimal flow-path length to ensure rapid quantification of PM-bound ROS.

\section{Instrument description}

\subsection{PINQ layout}

The flow diagram of the PINQ can be seen in Fig. 1, including all key components of the system and their corresponding connections through liquid and aerosol flows. The aerosol is collected in a novel instrument called the insoluble aerosol collector (IAC), in which PM is continuously collected into a liquid sample independent of size or chemical composition. The sample solution is then debubbled and passed through a purpose-built flow-through fluorimeter to quantify PM-bound ROS.

The standard sample flow rate for the instrument is 16.7 $\mathrm{L} \mathrm{min}^{-1}\left(1 \mathrm{~m}^{3} \mathrm{~h}^{-1}\right)$, which is set prior to sampling using a needle valve connected to vacuum. This has been found to be stable over $24 \mathrm{~h}$ sampling periods. The corresponding steam generator water supply for this flow rate is $1.5 \mathrm{~mL} \mathrm{~min}^{-1}$. All liquid flows are controlled using a peristaltic pump and hence are given in volumetric rather than mass units for completeness. The influence of temperature variation on liquid flow during normal laboratory conditions $\left(20-30^{\circ} \mathrm{C}\right)$ results in a negligible impact on instrument performance. In more extreme temperature environments it may be necessary to regulate liquid reservoir temperatures and correct for variations.

\subsection{The insoluble aerosol collector (IAC)}

The PINQs aerosol collection stage, the IAC, is categorized as a steam collection device. The sample aerosol is mixed with water vapour to generate a supersaturated aerosol in which the PM undergoes condensational growth. These grown particles are collected with a high efficiency into a continuously flowing sample solution inside a solvent resistant vortex collector. The system can be divided into four main sections: inlet, growth chamber, vortex collector, and steam generator.

\subsubsection{Inlet}

The IAC inlet is a $10 \mathrm{~mm}$ inner-diameter tube containing a $1 / 16$ in outer-diameter aluminium steam delivery tube concentric to the inlet, oriented in the direction of flow. A precisely controlled mass flow rate of water vapour is injected into the aerosol flow through this delivery tube. The aerosol and water vapour are then turbulently mixed through a $45^{\circ}$ expanding cone, creating a homogenous supersaturated mixture.

\subsubsection{Growth chamber}

The supersaturated aerosol is passed through a cylindrical growth chamber $(50 \mathrm{~mm}$ inner diameter, $140 \mathrm{~mm}$ length) to cool the mixture and allow time for particle condensational growth to occur. The chamber is actively liquid cooled to ambient temperature using a liquid cooling system and copper tubing compressed around the chamber to prevent any excess heat build-up in the system from the steam supply or aerosol sample. A drain at the base of the chamber removes excess condensation on the chamber walls. Grown particles exiting the growth chamber are accelerated through a $30^{\circ}$ contracting cone into the vortex collector.

\subsubsection{Solvent-resistant vortex collector}

The vortex collector is a specially designed aerosol capture device which collects particles into liquid regardless of solubility. The concept and dimensions are based on a wettedwall cyclone described previously in the literature (Orsini et al., 2008), with the named vortex collector introduced here to differentiate it from the design of a standard miniature PM cyclone (Gussman et al., 2002; Kenny et al., 2000). Both share similar geometries which are selected in order to create a stable air cyclone inside the device. However, whilst the PM cyclone deposits particles onto the solid surface of the cone, the vortex collector deposits particles directly into a collection liquid. This is achieved through the continuous injection and removal of liquid at the top and base of the cone, respectively. The inertial force of the air cyclone acts on the liquid as it passes through the cone, causing the liquid to spread on the cone wall and form a standing liquid vortex. Grown particles entering the collector from the growth chamber impact this liquid vortex and are captured directly into the liquid stream.

The condensational growth stage prior to the collector removes the significance of the cut-off size and shape which characterize PM cyclones. Instead, the main requirement is that particles are grown above the size at which maximum collection efficiency is achieved. As such, the dimensions specified in the literature regarding PM cyclones can be altered to achieve the desired standing liquid vortex without risking performance. In particular, the aerosol inlet and exit holes can be narrowed to accelerate the aerosol flow into the 


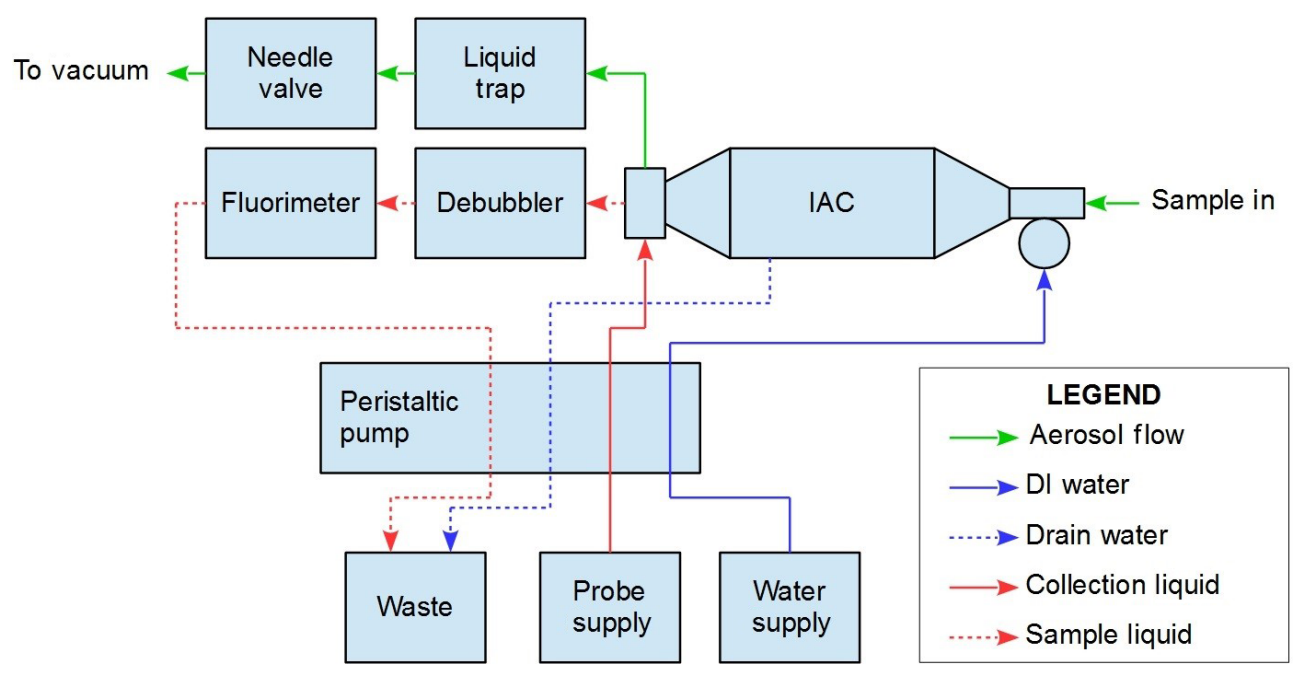

Figure 1. Diagram of the PINQ system showing all major components and the aerosol and liquid flow paths linking them.

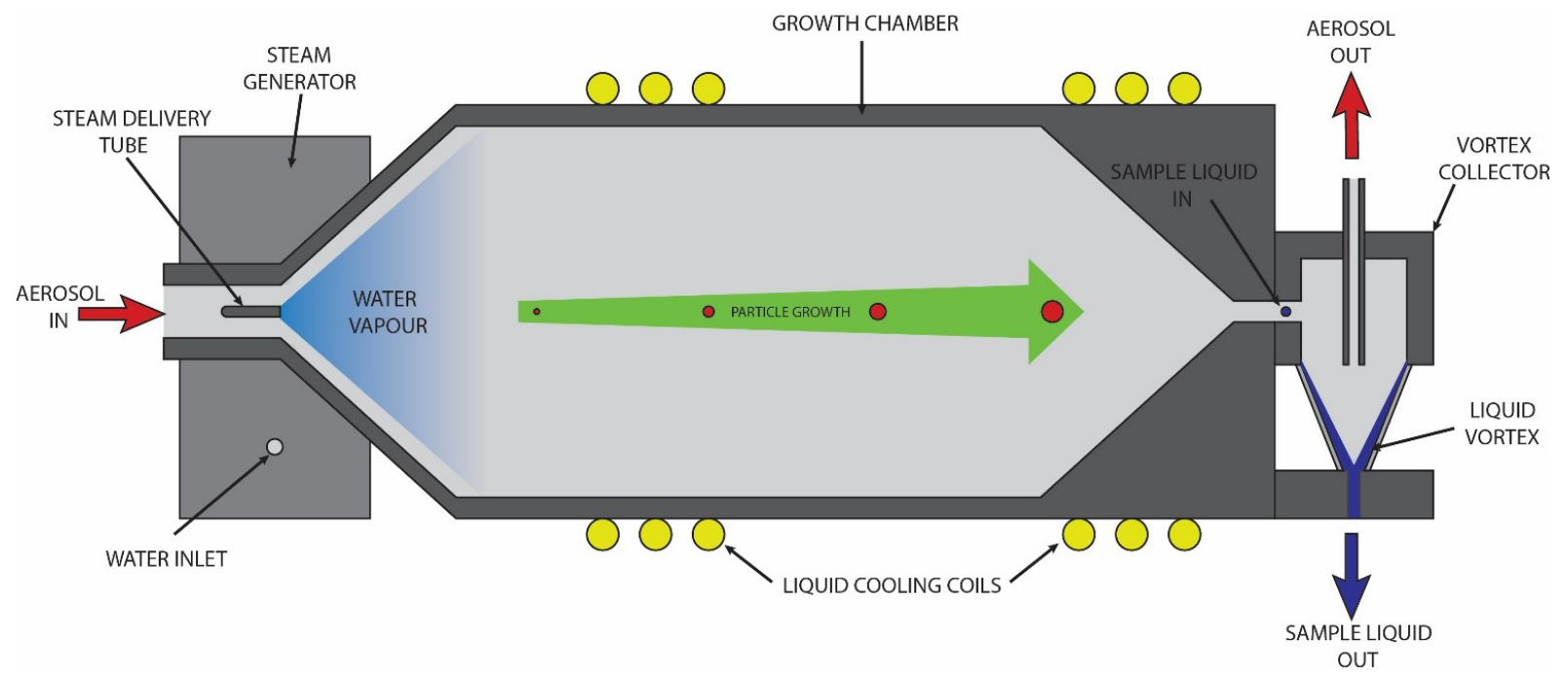

Figure 2. Diagram of the PINQ insoluble aerosol collector (IAC), showing key components including the aerosol inlet, steam generator, growth chamber, and vortex collector.

collector in order to better form a liquid vortex (Orsini et al., 2008). The location of liquid injection is also important, with the most stable vortex achieved when the liquid is injected into the aerosol stream before entering into the collector itself. Without these modifications the resulting collector does not form a standing liquid vortex for the direct collection of PM into liquid (Peltier et al., 2007). Instead it could be more aptly described as a washed-wall cyclone, with a lower reported collection efficiency for insoluble particles.

Beyond these design points other parameters governing the performance of the vortex collector, including liquid and aerosol flow rates, sample liquid, temperature, materials, and surface finish, making prediction of vortex formation difficult. To this end, the vortex collector was constructed using a combination of aluminium and stainless steel with a transpar- ent fluorinated ethylene propylene (FEP) cone. This ensures the instrument is solvent resistant for use with DMSO in the PINQ system, whilst also allowing for visual confirmation of vortex formation.

This device was chosen over simpler impaction methods for two reasons. First, the vortex collector collects particles directly into the liquid, allowing for solubility-independent particle collection. Second, the liquid vortex ensures that the collected PM is homogenously mixed with the sample liquid exiting the cone base. When integrated into the PINQ, this factor coupled with the diffusion-limited reaction between BPEAnit and collected ROS leads to the sample liquid exiting the base being fully reacted and ready for quantification. 


\subsubsection{Steam generator}

A stable and precisely controlled steam flow rate is essential for effective condensational growth of ultrafine particles. Initially a design similar to that described in the literature was used (Orsini et al., 2003), in which a regulated water flow was input into a heated stainless steel tube. A similar design was attempted with both one- and two-stage heating but was fraught with stability issues. This was attributed to the system having a low thermal mass, causing an unstable equilibrium point in the system. To remedy this issue, a new generator was proposed with a larger, insulated thermal mass.

The new generator design consisted of a cylindrical aluminium block sheathed in thermally insulating polytetrafluoroethylene (PTFE). The aluminium block contains a sealed internal chamber with a narrow inlet and exit holes bored perpendicularly at the base and top, respectively. The block is maintained at a constant temperature by the use of two heater cartridges and a thermocouple driven with a Novus N1020 PID controller. A flow of water regulated by a peristaltic pump is continuously input into the base of the chamber through the inlet hole, where it vaporizes and expands before being ejected through the exit hole. The aluminium steam delivery tube from the inlet section is inserted directly into the exit hole to minimize cooling and reduce the system size. This design greatly improved stability and allows for long periods of unattended sampling.

\subsection{Flow-through fluorimeter}

A compact flow-through fluorimeter was designed to provide fast and accurate measurements of sample fluorescence for ROS quantification. The sample liquid fluorescence is continuously measured in a small flow-through quartz cell contained within a stainless steel housing. The excitation source is a $450 \mathrm{~nm}$ diode laser, and the fluorescence response measured perpendicularly with an Oceanoptics USB2000+ spectrometer. The laser and spectrometer are directly mounted to the stainless steel housing to remove the need for optical fibre connections, reducing set-up complexity and minimizing size. The set-up is controlled using a dedicated LabVIEWbased application.

\section{Methodology}

This study is divided into two investigations. The first is the measurement of the IAC collection efficiency. The second is the characterization of the PINQ system fluorescence response. Flow diagrams of experimental set-ups, further methodology details, and calculations can be found in the Supplement.

\subsection{IAC characterization}

\subsubsection{Particle mass collection efficiency}

The collection efficiency of the IAC for both fine $\left(\mathrm{PM}_{2.5}\right)$ and ultrafine $\left(\mathrm{PM}_{0.1}\right)$ particles was investigated through the comparison of mass concentration of ammonium sulfate collected with the IAC and those collected onto membrane filters. The sample aerosol was generated using a solution of ammonium sulfate in DI water in a Mesa Labs 6 Jet Collision Nebulizer. Sample was dried and diluted to provide the required sample flow rate before being sampled by the IAC, filter (Whatman Nuclepore polycarbonate membrane, $25 \mathrm{~mm}$ diameter, $0.2 \mu \mathrm{m}$ pore size), and scanning mobility particle sizer (SMPS) (TSI 3071 Classifier, TSI 3772 Condensation Particle Counter, Aerosol Instrument Manager (AIM) software). IAC samples were collected into sealed quartz sample vials. Sample filters were collected and placed in quartz vials, where they were sonicated for $5 \mathrm{~min}$ in $1 \mathrm{~mL}$ of solution. Samples were refrigerated until ion chromatography (IC) analysis was performed by the Central Analytical Research Facility (CARF) based at the Queensland University of Technology (QUT). Measurements were performed using a Dionex Integrion High-Precision Ion Chromatography setup with a Dionex AS-AP autosampler. An AS18 Column $(150 \mathrm{~mm} \times 2 \mathrm{~mm})$ with an isocratic $0.30 \mathrm{~mL} \mathrm{~min}^{-1}$ flow was used and $0.1,1,5,10,20$, and $100 \mathrm{ppm}$ standards were used as calibration points.

\subsubsection{Size-dependent particle number collection efficiency}

The size-dependent particle number collection efficiency was investigated using di(2-ethylhexyl) sebacate (DEHS) particles. This was chosen as the droplet activation diameter is not dependent on the composition of the particles if they are hydrophobic (Andreae and Rosenfeld, 2008). Particles were generated using a Mesa Labs Single Jet Collision Nebulizer containing a solution of DEHS in ethanol. Monodisperse particle sizes were size-selected from the resulting polydisperse aerosol using an Electrostatic Classifier TSI 3071 for sizes between 30 and $300 \mathrm{~nm}$. The aerosol was then diluted to provide a sufficient sample aerosol flow rate. A three-way valve was used to rapidly switch between pre- and post-instrument sampling, with particle concentrations for each size found by averaging a 60 s sample from a TSI 3025 butanol-based CPC after system had stabilized. A Nafion dryer was attached to the CPC inlet to prevent the high humidity of the sample influencing measurements.

\subsection{PINQ characterization}

The PINQ was assembled for characterization as per the layout described in Fig. 1. A $1 \mu \mathrm{M}$ solution of BPEAnit in DMSO was prepared as the sample solution for the PINQ. A $1.5 \mathrm{~mL} \mathrm{~min}^{-1}$ steam generator water feed rate and a 
$1 \mathrm{~mL} \mathrm{~min}^{-1}$ sample flow rate were used. The PINQ inlet was connected to a three-way valve, with one port connected to a continuous supply of high-purity nitrogen gas and the other connected to a combustion sample chamber. A cigarette was left to smoulder in the sample chamber for $5 \mathrm{~min}$ before being extinguished. The PINQ then sampled continuously, with the supply switched between nitrogen gas and cigarette smoke every minute for a total of eight samples.

The fluorescent response of the BPEAnit probe is expressed as an equivalent nanomolar increase in the concentration of the methyl adduct of the probe (BPEAnit-Me). The conversion factor for this is found through the slope of a calibration curve generated from fluorescence measurements of BPEAnit-Me standards of various concentrations. For PINQ measurements this equivalent response is then normalized against the ratio of liquid supply flow rate to aerosol sample flow rate, resulting in a measure of PM-bound ROS in equivalent concentration of BPEAnit-Me per volume of air in nmol $\mathrm{m}^{-3}$ using Eq. (1). The limit of detection was calculated as 3 times the standard deviation of a set of $20 \mathrm{~s}$ blanks collected whilst sampling nitrogen.

$C_{\mathrm{ROS}}=\mathrm{FR} \cdot \mathrm{CF} \cdot \frac{q_{1 \mathrm{~s}}}{q_{\mathrm{A}}}$,

where $C_{\mathrm{ROS}}$ is the concentration of ROS in $\mathrm{nmol} \mathrm{m}^{-3}$, FR is the fluorescence response of the spectrometer in unitless counts, CF is the calibration factor calculated from the calibration curve calculated as nmol $\mathrm{L}^{-1}$ counts $^{-1}, q_{\text {ls }}$ is the liquid sample flow rate in $\mathrm{L} \mathrm{min}^{-1}$, and $q_{\mathrm{A}}$ is the aerosol sample flow rate in $\mathrm{m}^{3} \mathrm{~min}^{-1}$.

\section{Results and discussion}

\subsection{IAC characterization}

\subsubsection{Particle mass collection efficiency}

The IAC investigation was initially focused on mass collection efficiency in order to directly measure the fraction of aerosol collected into the sample liquid. As particle mass is proportional to the third order of particle size it was necessary to consider aerosols in terms of mass distribution when evaluating results. To this end, the averaged SMPS particle size distribution of the ammonium sulfate aerosol sample was fitted with a log-normal distribution and a corresponding mass distribution calculated. These distributions along with those of the ultrafine samples discussed below can be found in the Supplement. The ultrafine particles $\left(\mathrm{PM}_{0.1}\right)$ correspond to $3 \pm 5 \%$ of the total mass of the sample, whilst the entire mass distribution was in the fine particle size range $\left(\mathrm{PM}_{2.5}\right)$; hence the collection efficiency calculated using this aerosol is referred to as fine-particle collection efficiency. The averaged collection efficiency and standard error for the collected efficiency for fine particles is calculated as follows:

$\mathrm{CE}_{\text {fine }}=1.00 \pm 0.04$.

As the majority of the mass in the previous tests was contained in the particles larger than $100 \mathrm{~nm}(\sim 97 \%)$ this result does not necessarily indicate a high collection efficiency of ultrafine particles. Therefore, these experiments were repeated with the larger ammonium sulfate particles removed from the sample using an impactor as detailed in the Supplement Sect. S2.1. The averaged SMPS particle size distribution over the sample collection period was fitted with a log-normal distribution multiplied by a logistic function to emulate the size cut-off generated by the impactor, and a corresponding mass distribution was calculated. The ultrafine particles $(<100 \mathrm{~nm})$ correspond to $80 \pm 10 \%$ of the total mass of the sample, which is considerably higher than the previous size distribution.

The generated particle mass concentrations with the impactor in front of the atomiser (ultrafine particle experiment) were over 60 times lower than the $\mathrm{PM}_{2.5}$ experiments. In order to ensure the collected samples contained measurable concentrations of sulfate ions, the flow through the vortex collector was reduced from 1.00 to $0.15 \mathrm{~mL} \mathrm{~min}^{-1}$. This increased the residence time of the sample liquid in the vortex collector for the same aerosol flow rate, resulting in a more concentrated sample.

The averaged collection efficiency and corresponding standard error are calculated as follows:

$\mathrm{CE}_{\mathrm{ultrafine}}=1.05 \pm 0.06$.

The error of the ultrafine collection efficiency is larger than that of the fine collection due to the significantly lower aerosol sample concentration. However, the results are within error of each other, indicating that the IAC collects both fine and ultrafine particles with a very high efficiency. This is an expected result for steam collection devices, which will typically collect all particle sizes with equally high efficiency due to condensational growth of particles in the growth chamber well into the ultrafine size range.

\subsubsection{Steam dilution factor}

The sample liquid entering into the IAC was doped with a known quantity of sodium chloride. The steam dilution factor (SDF) was determined from the change in the chloride ion concentrations before and after the liquid feed passed through the vortex collector. Relevant measurements and individual calculated steam dilution factors for each sample can be found in the supplement. The average steam dilution factor for a standard liquid supply of $1 \mathrm{~mL} \mathrm{~min}^{-1}\left(\mathrm{SDF}_{\mathrm{SF}}\right)$ was calculated as follows:

$\mathrm{SDF}_{\mathrm{SF}}=0.882 \pm 0.004$

This corresponds to a $0.134 \pm 0.007 \mathrm{~mL} \mathrm{~min}^{-1}$ contribution of condensed water into the sample flow. 
The averaged steam dilution factor for a lowered liquid supply flow rate of $0.15 \mathrm{~mL} \mathrm{~min}^{-1}\left(\mathrm{SDF}_{\mathrm{LF}}\right)$ was calculated as follows:

$\mathrm{SDF}_{\mathrm{LF}}=0.527 \pm 0.007$

$\mathrm{SDF}_{\mathrm{LF}}$ is lower than that of the $\mathrm{SDF}_{\mathrm{SF}}$. This reduction indicates that the ratio of condensed water to sample flow rate has increased in the liquid sample exiting the PINQ. Despite this, the effective contribution of condensed water to the sample flow for $\mathrm{SDF}_{\mathrm{LF}}$ was calculated as $0.136 \pm 0.007 \mathrm{~mL} \mathrm{~min}^{-1}$, which is within the error of the condensation water contribution calculated for $\mathrm{SDF}_{\mathrm{SF}}$. This shows that the condensation rate in the sample is independent of liquid sample flow rate, PM mass, and particle number concentration (PNC). This indicates that the principle source of condensation in the sample is from inside the cyclone itself, which is directly proportional to the water flow rate input into the steam generator. This ensures that the steam dilution factor can be accurately corrected for in all measurements.

Lowering the liquid supply flow rate allows for higher concentrations of aerosol in the sample stream. In theory this could be further applied to improving the sensitivity of the PINQ. However, the corresponding increasing influence of steam dilution presents a limitation in the potential application of this. It is essential to keep the contribution of condensed water below $30 \%$ of the total sample $(\mathrm{SDF}>0.7$ ) when using a DMSO solution of the BPEAnit probe, as larger percentages of water in DMSO will cause a non-linear change in the fluorescent signal.

\subsubsection{Size-dependent hydrophobic particle collection efficiency}

Ammonium sulfate was selected as the test aerosol for the mass collection efficiency investigation due to its shape being close to spherical (Biskos et al., 2006) and detectability with ion chromatography. However, due to its high hygroscopicity it will undergo condensational growth at a much lower supersaturation than those required for hydrophobic aerosols (Popovicheva et al., 2008). To ensure that the collection efficiency is independent on the chemical composition of particles, measurements of the number concentration collection efficiency with hydrophobic particles were conducted.

Size-dependent hydrophobic particle number collection efficiency was measured through the size preclassification of DEHS aerosol and corresponding measurements of PNC entering and exiting the PINQ. Collection efficiency was corrected for inlet and chamber losses which were estimated to be 1 minus the lower limit of the ultrafine mass collection efficiency. The calculated particle number collection efficiencies at each tested size are shown in Fig. 3.

The mean collection efficiency was calculated as follows:

$\mathrm{CE}_{\mathrm{PNC}} \geq 0.97$
As it was not possible to generate sufficient DEHS test particles smaller than $30 \mathrm{~nm}$, the cut-off size corresponding to $50 \%$ of the maximum collection efficiency can only be extrapolated from the above graph to be $<20 \mathrm{~nm}$. This is an improvement on the earlier vortex-based wetted-wall cyclone design which reported a collection efficiency of $>0.88$ with a cut-off size of $30 \mathrm{~nm}$ (Orsini et al., 2008). It is also higher than the 0.69 collection efficiency reported by the washed miniature cyclone developed for organic carbon measurements (Peltier et al., 2007).

An important note in these comparisons is that the two variants found in the literature both used direct measurements of insoluble particles collected in liquid after exiting the instrument. The collection efficiency calculated here is the efficiency of initial collection into the liquid, and it would need to be corrected for losses in the liquid flow path between collector and detector for a full comparison. This was not explored as liquid line losses are not an issue in the application of the IAC in the PINQ. Reaction with the BPEAnit probe is effectively completed instantaneously upon collection, meaning particles lost in the liquid path have already fully reacted with the BPEAnit probe.

\subsection{PINQ characterization - response time and LOD}

The response time of the PINQ was separated into two parameters: a time delay between a source change and the corresponding start of change in fluorescence, and the mixing time taken for the fluorescence response to become completely independent of the previous source. An example of the fluorescence response of the BPEAnit probe when the instrument was switched from the ROS source (cigarette smoke) to nitrogen along with relevant key times is shown in Fig. 4. In the eight samples taken the signal strength of the cigarette smoke was approximately 60 times the magnitude of the background noise.

The averaged values of time delay and mixing time of the PINQ for the eight samples taken and corresponding standard errors were calculated as follows:

time delay $=6.3 \pm 0.6 \mathrm{~s}$

mixing time $=32 \pm 1 \mathrm{~s}$.

The time delay of $6.3 \mathrm{~s}$ represents a small time correction factor which does not strongly influence instrument performance. In contrast, the mixing time of $32 \mathrm{~s}$ is a key value in determining the limits of instrument time resolution. This value indicates the minimum averaging time, which provides independent data points, and is directly proportional to both the liquid sample flow rate and the internal liquid volume of the liquid sample flow path inside the instrument. An increased liquid sample flow rate above the tested $1 \mathrm{~mL} \mathrm{~min}^{-1}$ will result in a faster time resolution. However, this will occur at the cost of a lower ratio of collection liquid flow rate to aerosol sample flow rate, diluting the aerosol and reducing instrument sensitivity. Internal liquid volume was minimized 


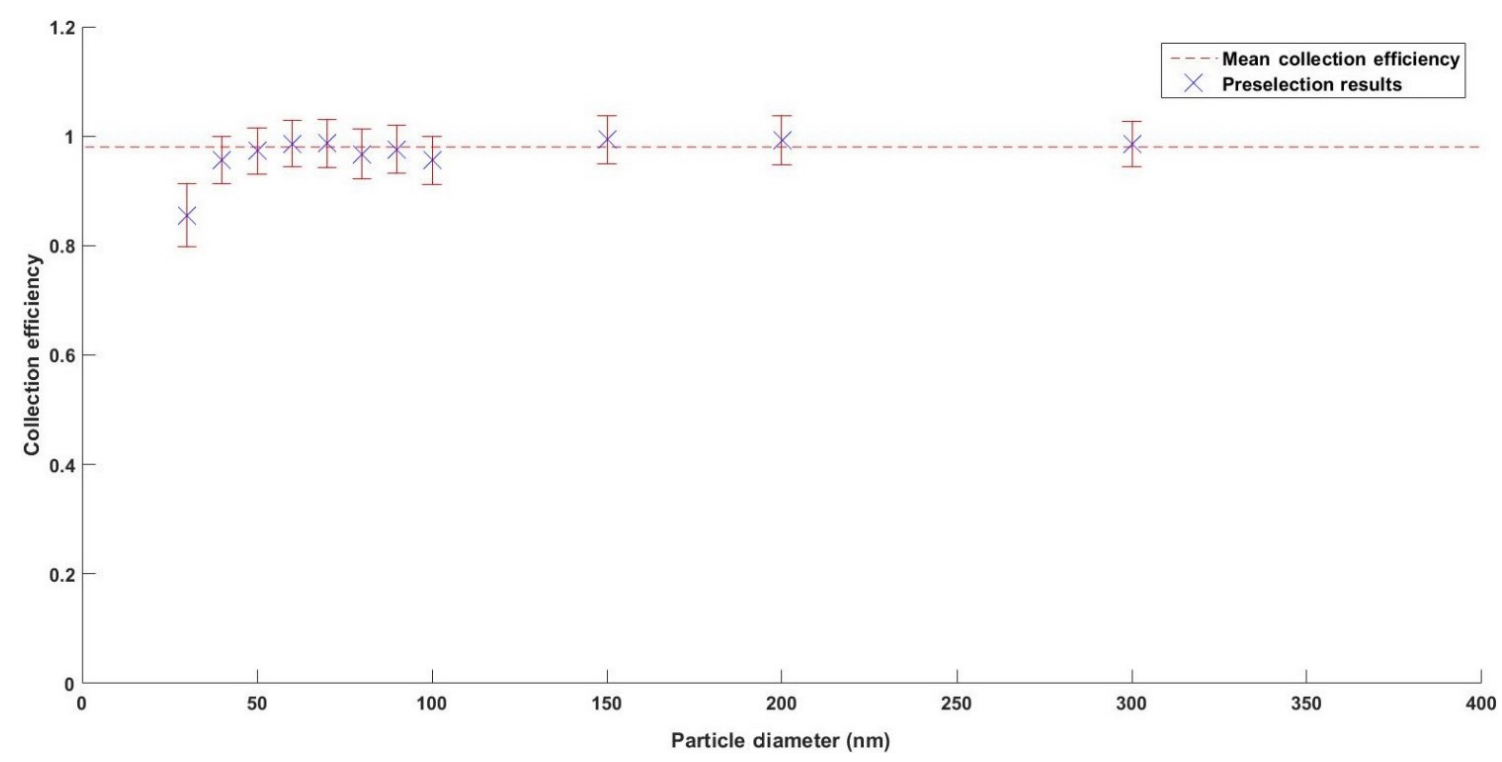

Figure 3. Calculated collection efficiencies for DEHS preselection measurements with standard error bars and mean collection efficiency.

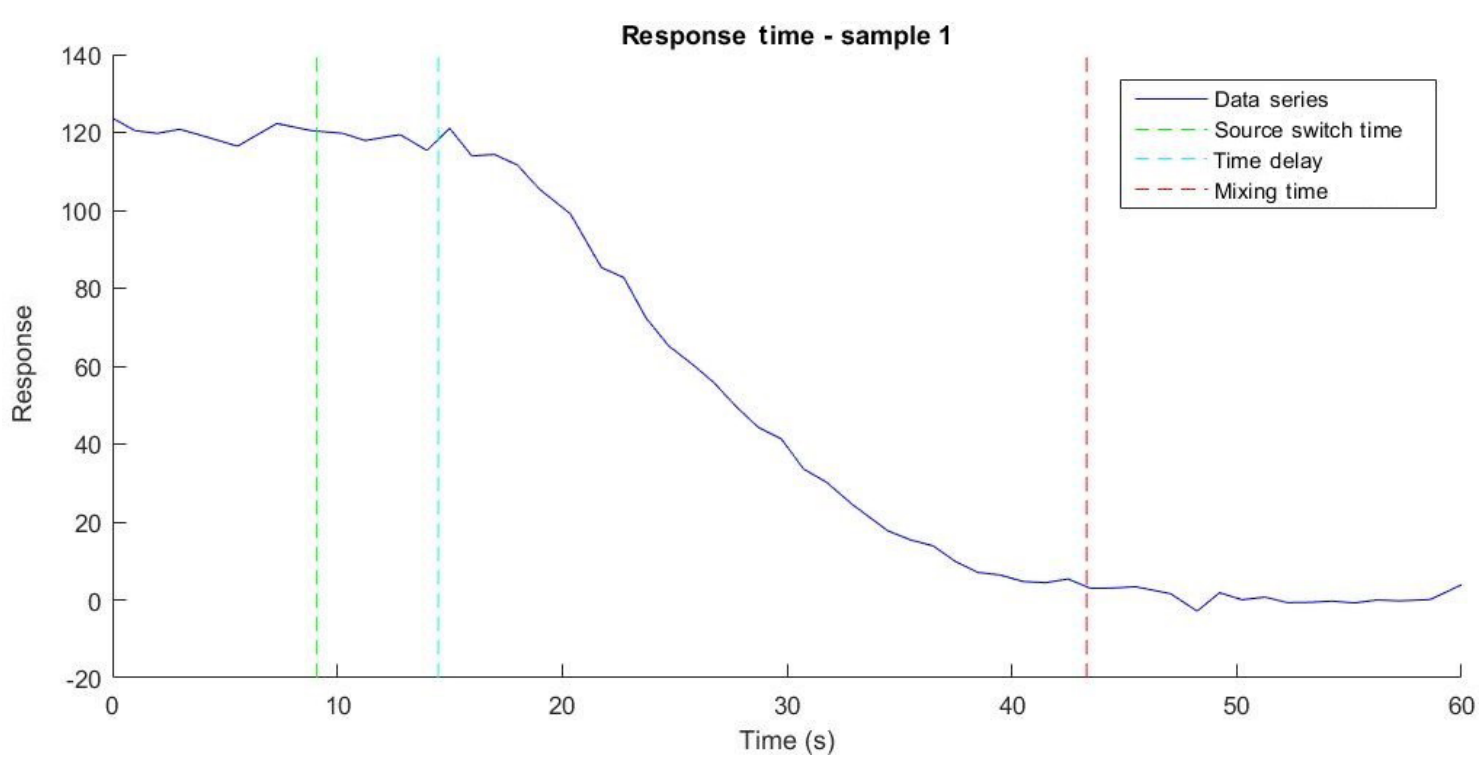

Figure 4. The fluorescence data series over time for the response time of Sample 1 with the time the source switched from cigarette smoke to nitrogen (source switch time), the time at which the fluorimeter began to measure a decrease in signal (response time delay), and the time at which the signal reduced to the background (mixing time delay).

through the use of small bore $1 / 16^{\prime \prime}$ OD tubing for all flow paths and a custom-made low internal volume fluorescence cell. An unavoidable limiting factor in reducing the mixing time is the internal volume of the cyclone, which cannot be minimized further without impacting the instrument performance.

The results of this experiment indicate that the system requires a total of $\sim 40 \mathrm{~s}$ to reach equilibrium response when connected to an aerosol source. When performing measurements on the PM-bound ROS it is necessary to account for any contributions from the gas phase by alternating sampling between the total aerosol source and the source after filtering to remove the particle-bound ROS. Therefore, the time resolution of the PINQ is determined by the sum of the total response time and the time required to average the signal for an accurate measurement. An averaging period of $20 \mathrm{~s}$ was selected, leading the PINQ to have a time resolution of $1 \mathrm{~min}$ when performing alternating gas- and total-phase measurements (see Sect. 4.3). A total of 234 blanks of $20 \mathrm{~s}$ averaging time sampled with nitrogen were collected and normalized as 
an equivalent nmol of BPEAnit-Me per cubic metre of air as detailed in Sect. 4.2. The limit of detection of the PINQ was determined as 3 times the standard deviation of these blanks.

LOD $=0.08 \frac{\mathrm{nmol}}{\mathrm{m}^{3}}$

The PINQ has a lower LOD than other online systems with responses normalized per volume of air sampled for two primary reasons. First, the IAC has a very small ratio of liquid sample flow to aerosol sample flow. This ensures a more highly concentrated sample than those of particle collectorbased systems, which reported LODs between $4 \mathrm{nmol} \mathrm{m}^{-3}$ (Wragg et al., 2016) and $2 \mathrm{nmol} \mathrm{m}^{-3}$ (Zhou et al., 2018). The GAC-ROS system has similar aerosol and liquid flows, resulting in a similarly concentrated samples and hence a closer LOD of $0.12 \mathrm{nmol} \mathrm{m}^{-3}$ (Huang et al., 2016a). The second factor contributing to the lower PINQ LOD is the different ROS probe used. The BPEAnit probe does not auto-oxidise in the same manner as the DCFH probe used by the other system discussed here, resulting in more stable blanks and hence a lower LOD.

\subsection{PINQ response - particle- and gas-phase contributions}

As has been shown in Sect. 4.1. the IAC stage of the PINQ collects PM with a very high collection efficiency. However, experiments with the PINQ system also show sensitivity to gas-phase products. In order to accurately quantify the PMbound ROS the PINQ response must be corrected for the gasphase contributions during measurements. This is achieved by alternately sampling with and without a HEPA filter, resulting in both particle- and gas-phase measurements. This method was chosen over the use of a gas denuder for two reasons. First, gas denuders can cause significant losses of ultrafine particles (Stevanovic et al., 2015). Second, the gas phase can contain significant concentrations of ROS (Stevanovic et al., 2017), which cannot be investigated if scrubbed with a gas denuder.

The exact mechanism and efficiency with which the IAC collects the gas-phase contribution is unknown. Likely it is a combination of the collection of water-soluble gas species during the condensational growth stage and DMSO soluble species during interactions with the collection liquid inside the vortex collector. The quantification of these effects is a complex issue as it will likely be dependent upon each gas species solubility in both water and DMSO. As such the gasphase response is considered semi-quantitative, with its characterization beyond the scope of this paper. Hence the PINQ is presented here as an instrument for the measurement of PM-bound ROS only.

\section{Summary}

This paper's first focus was on the design and characterization of the IAC as a high-efficiency aerosol collector for use in the PINQ system. It is defined as a steam collection device in which the sample aerosol is continuously mixed with a stream of water vapour to generate a supersaturated mixture, growing the particles into large liquid droplets to ensure high-efficiency capture independent of initial particle size. The grown droplets are collected continuously into a liquid vortex inside a specially designed vortex collector. This was designed over a simpler impaction system as it allows the capture of insoluble in the collection liquid. The vortex collector is also solvent resistant and allows for visual confirmation of the liquid vortex.

The IAC mass collection efficiency was determined to be within an error of 1.00 for both fine and ultrafine ammonium sulfate particles. This result indicates that, provided particles seed liquid droplets, they are collected with a very high collection efficiency. However, hydrophilic particles like ammonium sulfate will undergo condensational growth more readily than hydrophobic particles. As the IAC must collect particles independently of chemical composition for use in the PINQ system, the number collection efficiency of highly hydrophobic DEHS test particles was also investigated. Using these particles the number collection efficiency was found to be $>0.97$ with a cut-off size of $<20 \mathrm{~nm}$. This result shows that the IAC is capable of collecting particles with a high efficiency independent of particle size and composition.

The PINQ was developed to measure PM-bound ROS using the BPEAnit chemical probe in conjunction with the IAC. A $1 \mu \mathrm{M}$ solution of BPEAnit in DMSO is used as the sample collection liquid, with particles collected directly into the probe solution inside the IAC vortex collector. The rapid mixing of liquid inside the vortex coupled with the diffusion-limited reaction between the probe and any ROS collected ensures the liquid exiting the IAC is fully reacted. The sample liquid is then debubbled and input into a specially designed flow-through fluorimeter. Finally, the fluorescence response measured is converted into PM-bound ROS through calibrations performed on known concentrations of BPEAnit-ME and are expressed in $\mathrm{nmol} \mathrm{m}^{-3}$.

The PINQ is also sensitive to gas-phase ROS. Therefore, in order to quantify PM-bound ROS it is necessary to account for gas-phase contributions by periodically filtering the aerosol sample. Experiments on response time with a standard sample flow rate of $1 \mathrm{~mL} \mathrm{~min}^{-1}$ indicate that after switching sources the PINQ signal takes $\sim 40 \mathrm{~s}$ to reach equilibrium response. Therefore, with a $20 \mathrm{~s}$ sample averaging time the sample time resolution of the instrument is 1 min when alternating between filtered and unfiltered samples. With this time resolution the LOD of the instrument was determined to be $0.08 \mathrm{nmol} \mathrm{m}^{-3}$. Both the time resolution and LOD of the instrument are considerably lower than other instruments currently found in the literature, indicating 
that the PINQ is a viable candidate for the quantification of PM-bound ROS.

Data availability. Collection efficiency of PINQ data is available as part of an online supplement. For a more detailed description on the design and construction of the instrument or instrument evaluation, please contact the corresponding author.

Supplement. The supplement related to this article is available online at: https://doi.org/10.5194/amt-12-2387-2019-supplement.

Author contributions. RAB improved and finalized the design of PINQ, set up the experiment, performed data analysis, and wrote the manuscript. SS made the initial design of the device, contributed to the experimental design, assisted with data interpretation, and reviewed the manuscript. SB reviewed the manuscript and contributed to the experimental design and data interpretation. ZDR came up with the original idea, contributed to the experimental design, assisted with data interpretation, and reviewed the manuscript.

Competing interests. The authors declare that they have no conflict of interest.

Acknowledgements. The authors wish to thank the following groups and institutions for their contribution to this work: the aerosol physics group at Tampere University of Technology (TUT) for their assistance in the characterization of the initial version of the device, Central Analytical Research Facility (CARF) for their assistance with ion chromatography analysis, and the Design and Manufacturing Centre (DMC) team from Queensland University of Technology for their help with the design and building of this device. This research was funded by ARC Discovery grant DP120100126 Fundamental study into the role of the organic fraction on the toxicity of combustion generated airborne particles and EU FP7 project ID: 308524, CITI-SENSE Development of sensor-based Citizens' Observatory Community for improving quality of life in cities.

Review statement. This paper was edited by William R. Simpson and reviewed by two anonymous referees.

\section{References}

Andreae, M. O. and Rosenfeld, D.: Aerosol-cloudprecipitation interactions, Part 1. The nature and sources of cloud-active aerosols, Earth-Sci. Rev., 89, 13-41, https://doi.org/10.1016/j.earscirev.2008.03.001, 2008.

Ayres, J. G., Borm, P., Cassee, F. R., Castranova, V., Donaldson, K., Ghio, A., Harrison, R. M., Hider, R., Kelly, F., Kooter, I. M., Marano, F., Maynard, R. L., Mudway, I., Nel, A., Sioutas, C., Smith, S., Baeza-Squiban, A., Cho, A., Duggan, S., and
Froines, J.: Evaluating the toxicity of airborne particulate matter and nanoparticles by measuring oxidative stress potential a workshop report and consensus statement, Inhal. Toxicol., 20, 75-99, https://doi.org/10.1080/08958370701665517, 2008.

Benbrahim-Tallaa, L., Baan, R., Grosse, Y., Secretan-Lauby, B., El Ghissassi, F., Bouvard, V., Guha, N., Loomis, D., and Straif, K.: Carcinogenicity of diesel-engine and gasoline-engine exhausts and some Nitroarènes, Pollut. Atmos., 13, 43-44, https://doi.org/10.1016/S1470-2045(12)70280-2, 2012.

Biskos, G., Paulsen, D., Russell, L. M., Buseck, P. R., and Martin, S. T.: Prompt deliquescence and efflorescence of aerosol nanoparticles, Atmos. Chem. Phys., 6, 4633-4642, https://doi.org/10.5194/acp-6-4633-2006, 2006.

Blinco, J. P., Fairfull-Smith, K. E., Morrow, B. J., and Bottle, S. E.: Profluorescent Nitroxides as Sensitive Probes of Oxidative Change and Free Radical Reactions, Aust. J. Chem., 64, 373389, https://doi.org/10.1071/CH10442, 2011.

Brines, M., Dall'Osto, M., Beddows, D. C. S., Harrison, R. M., Gómez-Moreno, F., Núñez, L., Artíñano, B., Costabile, F., Gobbi, G. P., Salimi, F., Morawska, L., Sioutas, C., and Querol, X.: Traffic and nucleation events as main sources of ultrafine particles in high-insolation developed world cities, Atmos. Chem. Phys., 15, 5929-5945, https://doi.org/10.5194/acp15-5929-2015, 2015.

Cho, A. K., Sioutas, C., Miguel, A. H., Kumagai, Y., Schmitz, D. A., Singh, M., Eiguren-Fernandez, A., and Froines, J. R.: Redox activity of airborne particulate matter at different sites in the Los Angeles Basin, Environ. Res., 99, 40-47, 2005.

Chow, J. C., Watson, J. G., Mauderly, J. L., Costa, D. L., Wyzga, R. E., Vedal, S., Hidy, G. M., Altshuler, S. L., Marrack, D., Heuss, J. M., Wolff, G. T., Pope, C. A., Dockery, D. W., Poperd, C. A., and Dockery, D. W.: Health effects of fine particulate air pollution: lines that connect, J. Air Waste Ma., 56, 707-708, https://doi.org/10.1080/10473289.2006.10464545, 2006.

Delfino, R. J., Staimer, N., Tjoa, T., Arhami, M., Polidori, A., Gillen, D. L., George, S. C., Shafer, M. M., Schauer, J. J., Sioutas, C., Ralph, C., Delfino, J., and Sioutash, C.: Associations of Primary and Secondary Organic Aerosols With Airway and Systemic Inflammation in an Elderly Panel Cohort, Source Epidemiol., 21, 892-902, 2010.

Donaldson, K., Stone, V., Seaton, A., and MacNee, W.: Ambient Particle Inhalation and the Cardiovascular System: Potential Mechanisms, Environ. Health Perspect., 109, 523-527, 2001.

Donaldson, K., Brown, D., Clouter, A., Duffin, R., Macnee, W., Renwick, L., Tran, L., and Stone, V.: The Pulmonary Toxicology of Ultrafine Particles, J. Aerosol. Med., 15, 213-220, 2002.

Dong, H. B., Zeng, L. M., Hu, M., Yu, Y. S., Zhang, Y. H., Slanina, J., Zheng, M., Wang, Z. F., and Jansen, R.: Technical Note: The application of an improved gas and aerosol collector for ambient air pollutants in China, Atmos. Chem. Phys., 12, 10519-10533, https://doi.org/10.5194/acp-12-10519-2012, 2012.

Eiguren-Fernandez, A., Kreisberg, N., and Hering, S.: An online monitor of the oxidative capacity of aerosols (o-MOCA), Atmos. Meas. Tech., 10, 633-644, https://doi.org/10.5194/amt-10-6332017, 2017.

Fairfull-Smith, K. E. and Bottle, S. E.: The Synthesis and Physical Properties of Novel Polyaromatic Profluorescent Isoindoline Nitroxide Probes, European J. Org. Chem., 2008, 5391-5400, https://doi.org/10.1002/ejoc.200800597, 2008. 
Fang, T., Verma, V., Guo, H., King, L. E., Edgerton, E. S., and Weber, R. J.: A semi-automated system for quantifying the oxidative potential of ambient particles in aqueous extracts using the dithiothreitol (DTT) assay: results from the Southeastern Center for Air Pollution and Epidemiology (SCAPE), Atmos. Meas. Tech., 8, 471-482, https://doi.org/10.5194/amt-8471-2015, 2015.

Fang, T., Verma, V., T Bates, J., Abrams, J., Klein, M., Strickland, J. M., Sarnat, E. S., Chang, H. H., Mulholland, A. J., Tolbert, E. P., Russell, G. A., and Weber, J. R.: Oxidative potential of ambient water-soluble $\mathrm{PM}_{2.5}$ in the southeastern United States: Contrasts in sources and health associations between ascorbic acid (AA) and dithiothreitol (DTT) assays, Atmos. Chem. Phys., 16, 38653879, https://doi.org/10.5194/acp-16-3865-2016, 2016.

Fuller, S. J., Wragg, F. P. H., Nutter, J., and Kalberer, M.: Comparison of on-line and off-line methods to quantify reactive oxygen species (ROS) in atmospheric aerosols, Atmos. Environ., 92, $97-$ 103, https://doi.org/10.1016/j.atmosenv.2014.04.006, 2014.

Gao, D., Fang, T., Verma, V., Zeng, L., and Weber, R. J.: A method for measuring total aerosol oxidative potential (OP) with the dithiothreitol (DTT) assay and comparisons between an urban and roadside site of water-soluble and total OP, Atmos. Meas. Tech., 10, 2821-2835, https://doi.org/10.5194/amt10-2821-2017, 2017.

Gussman, R. A., Kenny, L. C., Labickas, M., and Norton, P.: Design, Calibration, and Field Test of a Cyclone for $\mathrm{PM}_{1}$ Ambient Air Sampling, Aerosol Sci. Technol., 36, 361-365, https://doi.org/10.1080/027868202753504461, 2002.

Harrison, R. M. and Yin, J.: Particulate matter in the atmosphere: Which particle properties are important for its effects on health?, Sci. Total Environ., 249, 85-101, https://doi.org/10.1016/S00489697(99)00513-6, 2000

Hasson, A. S. and Paulson, S. E.: An investigation of the relationship between gas-phase and aerosol-borne hydroperoxides in urban air, J. Aerosol Sci., 34, 459-468, https://doi.org/10.1016/S0021-8502(03)00002-8, 2003.

Hedayat, F., Stevanovic, S., Miljevic, B., Bottle, S., and Ristovski, Z. D. D.: Review-evaluating the molecular assays for measuring the oxidative potential of particulate matter, Chem. Ind. Chem. Eng. Q., 21, 201-210, https://doi.org/10.2298/CICEQ140228031H, 2015.

Hering, S. V., Spielman, S. R., and Lewis, G. S.: Moderated Water Based Condensational Particle Growth in a Laminar Flow, Aerosol Sci. Technol., 48, 401-408, https://doi.org/10.1080/02786826.2014.881460, 2014.

Huang, W., Zhang, Y., Zhang, Y., Zeng, L., Dong, H., Huo, P., Fang, D., and Schauer, J. J.: Development of an automated sampling-analysis system for simultaneous measurement of reactive oxygen species (ROS) in gas and particle phases: GAC-ROS, Atmos. Environ., 134, 18-26, https://doi.org/10.1016/j.atmosenv.2016.03.038, 2016a.

Huang, W., Zhang, Y., Zhang, Y., Fang, D., and Schauer, J. J.: Optimization of the Measurement of Particle-Bound Reactive Oxygen Species with $2^{\prime}, 7^{\prime}$-dichlorofluorescin (DCFH), Water. Air. Soil Pollut., 227, p. 164, https://doi.org/10.1007/s11270016-2860-9, 2016b.

Hung, H.-F. and Wang, C.-S.: Experimental determination of reactive oxygen species in Taipei aerosols, J. Aerosol Sci., 32, 12011211, https://doi.org/10.1016/S0021-8502(01)00051-9, 2001.
Kao, M. C. and Wang, C.-S.: Reactive Oxygen Species in Incense Smoke, Aerososl Air Qual. Res., 2, 61-69, 2002.

Kenny, L. C., Gussman, R., and Meyer, M.: Development of a Sharp-Cut Cyclone for Ambient Aerosol Monitoring Applications, Aerosol Sci. Technol., 32, 338-358, https://doi.org/10.1080/027868200303669, 2000.

Khlystov, A.: The steam-jet aerosol collector, Atmos. Environ., 29, 2229-2234, https://doi.org/10.1016/1352-2310(95)00180-7, 1995.

Kidwell, C. B. and Ondov, J. M.: Development and Evaluation of a Prototype System for Collecting Sub-Hourly Ambient Aerosol for Chemical Analysis, Aerosol Sci. Technol., 35, 596-601, 2010.

King, L. E. and Weber, R. J.: Development and testing of an online method to measure ambient fine particulate reactive oxygen species (ROS) based on the $2^{\prime}, 7^{\prime}$ dichlorofluorescin (DCFH) assay, Atmos. Meas. Tech., 6, 16471658, https://doi.org/10.5194/amt-6-1647-2013, 2013.

Koehler, K., Shapiro, J., Sameenoi, Y., Henry, C., and Volckens, J.: Laboratory evaluation of a microfluidic electrochemical sensor for aerosol oxidative load, Aerosol Sci. Technol., 48, 489-497, https://doi.org/10.1080/02786826.2014.891722, 2014.

Li, N., Sioutas, C., Cho, A., Schmitz, D., Misra, C., Sempf, J., Wang, M., Oberley, T., Froines, J., and Nel, A.: Ultrafine Particulate Pollutants Induce Oxidative Stress and Mitochondrial Damage, Environ. Health Perspect., 111, 455-460, https://doi.org/10.1289/ehp.6000, 2002.

Li, Q., Wyatt, A., and Kamens, R. M.: Oxidant generation and toxicity enhancement of aged-diesel exhaust, Atmos. Environ., 43, 1037-1042, https://doi.org/10.1016/j.atmosenv.2008.11.018, 2009.

Ma, Q., Cai, S., Wang, S., Zhao, B., Martin, R. V., Brauer, M., Cohen, A., Jiang, J., Zhou, W., Hao, J., Frostad, J., Forouzanfar, M. H., and Burnett, R. T.: Impacts of coal burning on ambient $\mathrm{PM}_{2.5}$ pollution in China, Atmos. Chem. Phys., 17, 4477-4491, https://doi.org/10.5194/acp-17-4477-2017, 2017.

Miljevic, B., Fairfull-Smith, K. E., Bottle, S. E., and Ristovski, Z. D.: The application of profluorescent nitroxides to detect reactive oxygen species derived from combustion-generated particulate matter: Cigarette smoke - A case study, Atmos. Environ., 44, 2224-2230, https://doi.org/10.1016/j.atmosenv.2010.02.043, 2010 .

Miljevic, B., Hedayat, F., Stevanovic, S., Fairfull-Smith, K. E., Bottle, S. E., and Ristovski, Z. D.: To sonicate or not to sonicate PM filters: Reactive Oxygen Species generation upon ultrasonic irradiation, Aerosol Sci. Technol., 48, 1276-1284, https://doi.org/10.1080/02786826.2014.981330, 2014.

Morgan, T. E., Davis, D. A., Iwata, N., Tanner, J. A., Snyder, D., Ning, Z., Kam, W., Hsu, Y.-T. T., Winkler, J. W., Chen, J.-C. C., Petasis, N. A., Baudry, M., Sioutas, C., and Finch, C. E.: Glutamatergic neurons in rodent models respond to nanoscale particulate urban air pollutants in vivo and in vitro, Environ. Health Perspect., 119, 1003-1009, https://doi.org/10.1289/ehp.1002973, 2011.

Mudway, I. S., Duggan, S. T., Venkataraman, C., Habib, G., Kelly, F. J., and Grigg, J.: Combustion of dried animal dung as biofuel results in the generation of highly redox active fine particulates, Part. Fibre Toxicol., 2, p. 6, https://doi.org/10.1186/1743-89772-6, 2005. 
Nel, A.: Air Pollution-Related Illness: Effects of Particles, Science, 308, 804-806, https://doi.org/10.1126/science.1108752, 2005.

Orsini, D. A., Ma, Y., Sullivan, A., Sierau, B., Baumann, K., and Weber, R. J.: Refinements to the particle-into-liquid sampler (PILS) for ground and airborne measurements of water soluble aerosol composition, Atmos. Environ., 37, 1243-1259, https://doi.org/10.1016/S1352-2310(02)01015-4, 2003.

Orsini, D. A., Rhoads, K., McElhoney, K., Schick, E., Koehler, D., and Hogrefe, O.: A Water Cyclone to Preserve Insoluble Aerosols in Liquid Flow - An Interface to Flow Cytometry to Detect Airborne Nucleic Acid, Aerosol Sci. Technol., 42, 343356, https://doi.org/10.1080/02786820802072881, 2008.

Pal, A. K., Bello, D., Budhlall, B., Rogers, E., and Milton, D. K.: Screening for Oxidative Stress Elicited by Engineered Nanomaterials: Evaluation of Acellular DCFH Assay, Dose. Response., 10, 308-330, https://doi.org/10.2203/dose-response.10-036.Pal, 2012.

Peltier, R. E., Weber, R. J., and Sullivan, A. P.: Investigating a Liquid-Based Method for Online Organic Carbon Detection in Atmospheric Particles, Aerosol Sci. Technol., 41, 1117-1127, https://doi.org/10.1080/02786820701777465, 2007.

Penttinen, P., Timonen, K. L., Tiittanen, P., Mirme, A., Ruuskanen, J., and Pekkanen, J.: Ultrafine particles in urban air and respiratory health among adult asthmatics, Eur. Respir. J., 17, 428-435, https://doi.org/10.1183/09031936.01.17304280, 2001.

Popovicheva, O., Persiantseva, N. M., Shonija, N. K., Demott, P., Koehler, K., Petters, M., Kreidenweis, S., Tishkova, V., Demirdjian, B., and Suzanne, J.: Water interaction with hydrophobic and hydrophilic soot particles, Phys. Chem. Chem. Phys., 10, 23322344, https://doi.org/10.1039/b718944n, 2008.

Posner, L. N. and Pandis, S. N.: Sources of ultrafine particles in the Eastern United States, Atmos. Environ., 111, 103-112, https://doi.org/10.1016/j.atmosenv.2015.03.033, 2015.

Puthussery, J. V., Zhang, C., and Verma, V.: Development and field testing of an online instrument for measuring the realtime oxidative potential of ambient particulate matter based on dithiothreitol assay, Atmos. Meas. Tech., 11, 5767-5780, https://doi.org/10.5194/amt-11-5767-2018, 2018.

Ristovski, Z. D., Miljevic, B., Surawski, N. C., Morawska, L., Fong, K. M., Goh, F., and Yang, I. A.: Respiratory health effects of diesel particulate matter, Respirology, 17, 201-212, https://doi.org/10.1111/j.1440-1843.2011.02109.x, 2012.

Sa, A., Daher, N., Shafer, M. M., Schauer, J. J., Sioutas, C., Saffari, A., Daher, N., Shafer, M. M., Schauer, J. J., and Sioutas, C.: Global Perspective on the Oxidative Potential of Airborne Particulate Matter: A Synthesis of Research Findings, Environ. Sci. Technol., 48, 7576-7583, https://doi.org/10.1021/es500937x, 2014.

Sabaliauskas, K., Jeong, C. H., Yao, X., Jun, Y. S., and Evans, G.: Cluster analysis of roadside ultrafine particle size distributions, Atmos. Environ., 70, 64-74, https://doi.org/10.1016/j.atmosenv.2012.12.025, 2013.

Sameenoi, Y., Koehler, K., Shapiro, J., Boonsong, K., Sun, Y., Collett, J., Volckens, J., and Henry, C. S.: Microfluidic electrochemical sensor for on-line monitoring of aerosol oxidative activity, J. Am. Chem. Soc., 134, 10562-10566, https://doi.org/10.1021/ja3031104, 2012.

Sameenoi, Y., Panymeesamer, P., Supalakorn, N., Koehler, K., Chailapakul, O., Henry, C. S., and Volckens, J.: Mi- crofluidic paper-based analytical device for aerosol oxidative activity, Environ. Sci. Technol., 47, 932-940, https://doi.org/10.1021/es304662w, 2013.

Shi, T., Duffin, R., Borm, P. J. A., Li, H., Weishaupt, C., and Schins, R. P. F.: Hydroxyl-radical-dependent DNA damage by ambient particulate matter from contrasting sampling locations, Environ. Res., 101, 18-24, https://doi.org/10.1016/j.envres.2005.09.005, 2006.

Shima, H., Koike, E., Shinohara, R., and Kobayashi, T.: Oxidative ability and toxicity of $\mathrm{n}$-hexane insoluble fraction of diesel exhaust particles, Toxicol. Sci., 91, 218-226, https://doi.org/10.1093/toxsci/kfj119, 2006.

Silverman, D. T., Samanic, C. M., Lubin, J. H., Blair, A. E., Stewart, P. A., Vermeulen, R., Coble, J. B., Rothman, N., Schleiff, P. L., Travis, W. D., Ziegler, R. G., Wacholder, S., and Attfield, M. D.: The Diesel Exhaust in Miners study: a nested case-control study of lung cancer and diesel exhaust, J. Natl. Cancer Inst., 104, 855868, https://doi.org/10.1093/jnci/djs034, 2012.

Simon, P. K. and Dasgupta, P. K.: Wet Effluent Denuder Coupled Liquid/Ion Chromatography Systems: Annular and Parallel Plate Denuders, Anal. Chem., 65, 1134-1139, https://doi.org/10.1021/ac00057a006, 1993.

Simon, P. K. and Dasgupta, P. K.: Continuous Automated Measurement of the Soluble Fraction of Atmospheric Particulate Matter, Anal. Chem., 67, 71-78, https://doi.org/10.1021/ac00097a012, 1995.

Simoneit, B. R. T., Kobayashi, M., Mochida, M., Kawamura, K., Lee, M., Lim, H. J., Turpin, B. J., and Komazaki, Y.: Composition and major sources of organic compounds of aerosol particulate matter sampled during the ACE-Asia campaign, J. Geophys. Res.-Atmos., 109, D19S10, https://doi.org/10.1029/2004JD004598, 2004.

Stevanovic, S., Ristovski, Z. D., Miljevic, B., Fairfull-Smith, K. E., and Bottle, S. E.: Application of profluorescent nitroxides for measurements of oxidative capacity of combustion generated particles, Chem. Ind. Chem. Eng. Q., 18, 653-659, 2012a.

Stevanovic, S., Miljevic, B., Eaglesham, G. K., Bottle, S. E., Ristovski, Z. D., and Fairfull-Smith, K. E.: The use of a nitroxide probe in DMSO to capture free radicals in particulate pollution, European J. Org. Chem., 2012, 5908-5912, https://doi.org/10.1002/ejoc.201200903, 2012b.

Stevanovic, S., Miljevic, B., Madl, P., Clifford, S., and Ristovski, Z.: Characterisation of a Commercially Available Thermodenuder and Diffusion Drier for Ultrafine Particles Losses, Aerosol Air Qual. Res., 15, 357-363, https://doi.org/10.4209/aaqr.2013.12.0355, 2015.

Stevanovic, S., Vaughan, A., Hedayat, F., Salimi, F., Rahman, M. M., Zare, A., Brown, R. A. J., Brown, R. A. J., Wang, H., Zhang, Z., Wang, X., Bottle, S. E., Yang, I. A., and Ristovski, Z. D.: Oxidative potential of gas phase combustion emissions - An underestimated and potentially harmful component of air pollution from combustion processes, Atmos. Environ., 158, 227-235, https://doi.org/10.1016/j.atmosenv.2017.03.041, 2017.

Stoeger, T., Takenaka, S., Frankenberger, B., Ritter, B., Karg, E., Maier, K., Schulz, H., and Schmid, O.: Deducing in vivo toxicity of combustion-derived nanoparticles from a cellFree oxidative potency assay and Metabolic activation of organic compounds, Environ. Health Perspect., 117, 54-60, https://doi.org/10.1289/ehp.11370, 2009. 
Takeuchi, M., Ullah, S. M. R., and Dasgupta, P. K.: Continuous Collection of Soluble Atmospheric Particles with a Wetted Hydrophilic Filter, Anal. Chem., 77, 8031-8040, 2005.

Venkatachari, P. and Hopke, P. K.: Development and Laboratory Testing of an Automated Monitor for the Measurement of Atmospheric Particle-Bound Reactive Oxygen Species (ROS), Aerosol Sci. Technol., 42, 629-635, https://doi.org/10.1080/02786820802227345, 2008.

Venkatachari, P., Hopke, P. K., Brune, W. H., Ren, X., Lesher, R., Mao, J., and Mitchell, M.: Characterization of Wintertime Reactive Oxygen Species Concentrations in Flushing, New York, Aerosol Sci. Technol., 41, 97-111, https://doi.org/10.1080/02786820601116004, 2007.

Verma, V., Rico-Martinez, R., Kotra, N., King, L., Liu, J., Snell, T. W., and Weber, R. J.: Contribution of water-soluble and insoluble components and their hydrophobic/hydrophilic subfractions to the reactive oxygen species-generating potential of fine ambient aerosols, Environ. Sci. Technol., 46, 11384-11392, https://doi.org/10.1021/es302484r, 2012.

Wang, Y., Hopke, P. K., Sun, L., Chalupa, D. C., and Utell, M. J.: Laboratory and field testing of an automated atmospheric particle-bound reactive oxygen species sampling-analysis system, J. Toxicol., 2011, 419476-419479, https://doi.org/10.1155/2011/419476, 2011.
Weber, R. J., Orsini, D., Daun, Y., Lee, Y.-N. N., Klotz, P. J., and Brechtel, F.: A Particle-into-Liquid Collector for Rapid Measurement of Aerosol Bulk Chemical Composition, Aerosol Sci. Technol., 35, 718-727, https://doi.org/10.1080/02786820152546761, 2001.

Wragg, F. P. H., Fuller, S. J., Freshwater, R., Green, D. C., Kelly, F. J., and Kalberer, M.: An automated online instrument to quantify aerosol-bound reactive oxygen species (ROS) for ambient measurement and health-relevant aerosol studies, Atmos. Meas. Tech., 9, 4891-4900, https://doi.org/10.5194/amt-9-4891-2016, 2016.

Zhao, J. Y. and Hopke, P. K.: Concentration of Reactive Oxygen Species (ROS) in Mainstream and Sidestream Cigarette Smoke, Aerosol Sci. Technol., 46, 191-197, https://doi.org/10.1080/02786826.2011.617795, 2012.

Zhou, J., Bruns, E. A., Zotter, P., Stefenelli, G., Pévôt, A. S. H., Baltensperger, U., El-Haddad, I., and Dommen, J.: Development, characterization and first deployment of an improved online reactive oxygen species analyzer, Atmos. Meas. Tech., 11, 65-80, https://doi.org/10.5194/amt-11-65-2018, 2018. 